\title{
The Demographics of Public Participation Access When Communicating Environmental Risk
}

\author{
V. Beth Kuser Olsen' \\ Earth System Science Interdisciplinary Center, University of Maryland, \\ College Park, MD, United States \\ Gerald E. Galloway Jr. \\ Department of Civil and Environmental Engineering, University \\ of Maryland, College Park, MD, United States \\ Matthias Ruth \\ Faculty of Arts Department of Economics, University of Alberta, \\ Edmonton, $\mathrm{AB}$, Canada
}

\section{Abstract}

The interaction between humans and their environment is epitomized by climate change issues. Public engagement is essential to communicating anticipated changes and shifting risks. We investigated one such risk-flooding in the mid-Atlantic region of the United States. We examined the demographics of flood risk management meeting participants and found they were significantly older, English-only speakers, better educated, more affluent, and more likely to be homeowners than the United States Census Bureau data indicate for the region's population. The aggregate gender and ethnic representation of all communities reflected that of the region's population, but individual communities were much less diverse. These findings show that it is important for risk managers to organize meetings in many local communities in their jurisdiction to capture all demographically diverse sectors. Outreach efforts should adapt to target younger community members, non-English speakers, lowerwage earners, and renters.

Keywords: demographics, public engagement, risk management

1 Corresponding author: v.beth.olsen@gmail.com 


\section{Introduction}

When communicating environmental risk information, the intent is to reach out to all sectors of the at-risk population and engage them in risk reduction measures. Past studies show that certain segments of the population may be underrepresented at community meetings at which information is disseminated. Factors that may influence individual participation rates include income, ethnicity, education, gender, age, and home ownership (Abrahamse \& Steg, 2015; Adger et al., 2001; Bullinger et al., 2002; Claes Fornell International [CFI] Group, 2010; Cutter et al., 2008; Cutter et al., 2010; Hvistendahl, 2012; Ibarrarian \& Ruth, 2009; Leach, 2004; Miller, 2012; Patt et al., 2009; Tomblin et al., 2015; Worthington et al., 2012). Some communities choose not to participate in government insurance programs such as the United States (US) National Flood Insurance Program because they do not have the municipal funds to comply with the required prerequisites or do not trust programs sponsored by the federal government (Brown et al., 2016). Non-participants are most often poor or minority communities (Ibarrarian \& Ruth, 2009). These communities have limited assets to dedicate to risk reduction measures, limited access to credit markets from which to borrow needed funds, and less access to government officials who could introduce the communities to these programs (Ibarrarian \& Ruth, 2009). Segregated minority communities are less likely to participate in government outreach programs (Ibarrarian \& Ruth, 2009). This may be due to a lack of trust based on past experience with government programs (Ibarrarian \& Ruth, 2009). In other cases, receiving English-only information about the programs in brochures, websites, meeting announcements, and other communications may be a language barrier to attendance (Cutter et al., 2010; Ibarrarian \& Ruth, 2009). Cultural norms that differ from that assumed in the design of government programs, such as multiple families living in one housing unit, may also pose barriers (Ibarrarian \& Ruth, 2009).

These barriers to community participation also exist for individual households living within participating communities (Ibarrarian \& Ruth, 2009; Worthington et al., 2012). Those with low household income lack the resources to purchase high-quality, risk-protected land and the retrofits that make staying on risk-prone ground less hazardous (Adger et al., 2001; Cutter et al., 2010; Ibarrarian \& Ruth, 2009). This lack of resources may lead to the perception that a meeting on risk reduction is irrelevant (Abrahamse \& Steg, 2015). Other barriers to attendance for low-income households may include the cost of childcare, elder care (Cutter et al., 2003; Ibarrarian \& Ruth, 2009), and transportation to the meeting (Cutter et al., 2010; Ibarrarian \& Ruth, 2009). Low-wage earners also tend to have jobs that are less flexible (Adger et al., 2001; Ibarrarian \& Ruth, 2009), resulting in an inability to attend meetings scheduled during their work hours. A lack of education can result in less awareness of the program and associated meetings due to illiteracy (Atreya et al., 
2015; Cutter et al., 2010; Ibarrarian \& Ruth, 2009; Patt et al., 2009). Those with less education may not feel qualified to participate in community decision-making and defer to community members with more education to attend meetings and contribute to community decisions (Tomblin et al., 2015; Worthington et al., 2012).

Gender has the potential to play the strongest role in meeting participation. Women are more likely to be poor, be less educated, have less flexibility in their work schedule, bear the greatest responsibility for childcare and elder care, and lack social status, resulting in the denial of participation in decision-making (Aberman et al., 2015; Cutter et al., 2003; Ibarrarian \& Ruth, 2009; Patt et al., 2009). These factors can lead to male-dominated meeting attendance.

Individuals who perceive their social status to be different from other meeting participants may avoid attending because they predict the experience will be unpleasant. Household income, ethnicity, gender, and education can contribute to perceived differences in social status (Cutter et al., 2003; Ibarrarian \& Ruth, 2009; Patt et al., 2009).

Whether an individual owns or rents their home may affect participation (CFI Group, 2010; Cutter et al., 2003, 2008, 2010). For example, those renting may perceive the responsibility for reducing risk as belonging to the property owner and may consider the meetings irrelevant.

Age can also be a factor (Cutter et al., 2010). The elderly are more likely to have health conditions that prevent attendance (Cutter et al., 2003; Ibarrarian \& Ruth, 2009). Lack of personal contact and distrust of strangers decreases their access to these programs (Ibarrarian \& Ruth, 2009).

Climate change issues involve multiple categories of environmental risk. Public engagement is essential to communicating anticipated changes and shifting risks. We investigated one such risk-flooding in the mid-Atlantic region of the US. While environmental risk is considered one of the most important aspects, climate change has major effects on many aspects of ecosystem functioning and human well-being. Our findings may be useful when considering outreach events in communities affected by other aspects of climate change, such as severe droughts, wildfires, and heat waves. We examined the demographics of flood risk management meeting participants to determine whether all sectors of the at-risk population were reached through this method of communication. Data were collected during US Federal Emergency Management Agency (FEMA)-endorsed, community-level flood risk management meetings (D. Bollinger, personal communication, February 6, 2013) within FEMA Region III. This is the mid-Atlantic region of the US encompassing Washington, DC, and the states of Delaware, Maryland, Pennsylvania, Virginia, and West Virginia (FEMA, 2014). During 2013, FEMA Region III scheduled flood risk review meetings in 16 counties and four cities, of which 71 affected communities were 
identified. For the purposes of our data collection, flood risk management meetings were held in the individual communities following the scheduled FEMA flood risk review meetings. We presented flood risk information specific to each community. From the 71 communities, 10 were randomly selected for our study. The number of communities was limited by available funding. The demographic characteristics of these communities were compared to data collected by the US Census Bureau (USCB) (USCB, 2010) to determine if those attending risk management meetings were a true representation of the population in FEMA Region III.

\section{Methods}

The selection of FEMA Region III communities for participation in the research was conducted in conjunction with FEMA Community Coordination and Outreach (CCO) meetings scheduled in 2013. CCO meetings introduce the most recent Digital Flood Insurance Rate Map (DFIRM) updates (D. Bollinger, personal communication, February 6, 2013; J. Janowicz, personal communication, February $16,2011)$ at the city or county municipal level. Property values are influenced by their location on the DFIRM because flood insurance rates and municipal building code requirements are tied to these maps. Communities scheduled for DFIRM updates were chosen because the updates served as an introduction to the topic of flood risk management. With awareness of the revised DFIRM, stakeholders in these communities were primed for the prospect of insurance rate changes. Therefore, they were likely to have the incentive to attend meetings that provided information about their flood risk.

The FEMA Region III Mitigation Outreach Coordinator introduced the lead researcher during city and county municipal level CCO meetings. The FEMA Coordinator endorsed the flood risk management meetings as a method by which the municipal leaders could disseminate flood risk information to local communities within their jurisdiction. The municipalities could earn points for participating in flood risk management meetings through the US National Flood Insurance Program Community Rating System that could reduce flood insurance rates throughout the city or county. The researcher presented a brief overview of the benefits of participation in the flood risk management meetings and the commitment required of the municipal leaders and community participants. The research project was described, including details about the survey and interview methods that would be used to test the effectiveness of the decision support systems utilized during the meeting. The municipal leaders were then asked to contact community organizers to arrange within the local community an introductory presentation through which this information was again presented by the researcher. For the purposes of our study, the definition of a community was a group of individuals within one geographical location who self-identified as cohesive in their interest in the sustainability of the 
socioeconomic well-being of those residing in that location. Following the local community introduction to the project, community organizers were asked to arrange a time and place for a flood risk management meeting at which data collection for the research would take place. Work schedules of community members and availability of a facility at which to hold the meeting were primary considerations for $70 \%$ of the communities in determining when the meeting was held. For $30 \%$ of the communities, the meeting date and time were selected primarily based on availability of a facility at which to hold the meeting. The first 10 communities in FEMA Region III to schedule a date and time for a flood risk management meeting were included in the research.

Community organizers were asked to advertise the event to stakeholders in their community. Most community organizers used multiple forms of media to advertise the meeting, including email correspondence, which was used by $80 \%$ of the community organizers. Other means of spreading the word included verbal announcements at regularly scheduled community meetings, telephone calls, paper flyers posted in the community, door-to-door delivery of paper flyers, community website or Facebook postings, and billboard displays. In all communities, advertising was provided in English only and no translators were provided at the meetings.

This method of local community outreach is standard practice when disseminating information about environmental issues affecting those communities (Leach, 2006a, 2006b; Leach et al., 2002; Lubell \& Leach, 2005). For flood risk issues, these meetings are held when new FEMA DFIRM updates become available at the city or county municipal level. In our study, we wanted to learn whether this type of outreach was effective in attracting all demographic sectors of the population. If so, the findings support the continuing use of this method of communicating flood risk. If not, a closer examination of the process and possible changes in outreach methods are warranted.

To measure the effectiveness of this methodology in attracting all demographic sectors, participants were asked to complete a written survey at the start of each flood risk management meeting. The survey included self-reported demographic information on their gender, age, race, education, language, household income, and home ownership. Each demographic category had at least two levels from which the participant was asked to choose. The number of levels and description of each matched those included in the USCB 2010 census (USCB, 2010). The data from each participant were pooled within the community where the flood risk management meeting was held so that the proportions at each level of each demographic characteristic surveyed could be described for that community. A total of 98 members within the 10 communities participated in the research. The size of each community varied from as small as 25 members to as large as 19,398. All but one had fewer than 1,100 members. The proportion of members within each community participating in the study ranged from less than $1 \%$ to $24 \%$ of 
total membership. The demographic information from all 10 communities were pooled into one group to describe the overall demographic characteristics of the study group. The analyses weighted this variable when calculating the aggregate because the communities in the study varied in size. This was compared to the demographic proportions of the FEMA Region III population that were collected during the USCB 2010 census at the state level. For the analyses in this study, the information for each state in FEMA Region III was combined to describe the region's population, resulting in a population size of 29,829,606 (USCB, 2010). The totals were normalized by calculating the region's proportions of the population at each level of each demographic characteristic surveyed. The proportions at the community level and the FEMA Region III population level were then compared. Univariate and multivariate statistical analyses were used to address whether participants in the flood risk management meetings were representative of all demographic sectors in the region's population.

\section{Univariate analyses}

The SurveyMeans procedure of the Statistical Analysis System (SAS Proprietary Software, version 9.3) was used for these analyses. To examine whether the demographic differences between the FEMA Region III population and the study's communities were significant, the proportions at each level within each demographic characteristic for the aggregate of the 10 communities were calculated. A 95\% confidence interval (CI) was calculated for each demographic characteristic: gender, age, race, language spoken, educational attainment, household income, and home ownership. The CI was the range of values for the proportions for each demographic level that would be expected to contain a population value, given a population size of $29,829,606$ and a sample size of 98 participants within 10 communities. The population proportions for each level within each demographic characteristic calculated using the USCB 2010 census were then identified as values within or outside the respective CI. If the population proportion was within the $\mathrm{CI}$, we concluded there was no significant difference between the demographic characteristic of the 10 communities and the general population in FEMA Region III. If the population proportion was outside the CI, the demographic characteristic of the 10 communities was considered significantly different from the general population in FEMA Region III. Where a significant difference was found, the community proportion was identified as either higher or lower than the population proportion. 


\section{Multivariate analyses}

The univariate analyses described demographic comparisons between the study's communities and the FEMA Region III population by independently examining each level within each demographic characteristic. A multivariate analysis was performed to simultaneously describe all levels of all seven demographic characteristics for each of the 10 communities in which a flood risk management meeting was conducted and for the FEMA Region III population. A unit that represented the aggregate of all 10 communities was included in this analysis. Ward's Minimum Variance Cluster Analysis, as outlined in the SAS TREE procedure (SAS Proprietary Software, version 9.3), grouped these communities in clusters based on their overall demographic similarity.

Principal component analysis was performed to address the interrelationships among the demographic characteristics using the SAS PRINCOMP procedure (SAS Proprietary Software, version 9.3). A multidimensional preference analysis based on the most informative principal components showed a visual representation of the relationships between each of the 10 communities, the FEMA Region III population, and vectors of each of the levels of the original demographic characteristics.

\section{Results}

Flood risk management meeting participants in the 10 communities were significantly older (see Figure 1), better educated (see Figure 2), wealthier (see Figure 3), more likely to own homes (see Figure 4), and spoke English only (see Figure 5) compared to the FEMA Region III population. The oldest and youngest ages were significantly higher and lower, respectively, in the 10 communities compared to the population in FEMA Region III (see Figure 1). Particularly noteworthy is that no meeting participants were in the 18-20-year age category, which was the youngest age group to whom the survey was offered. The youngest participants were in the 21-44-year age category. The study communities showed a significantly lower proportion of yearly household incomes below $\$ 35,000$ and a significantly higher proportion of yearly household incomes in the range of \$150,000-200,000 (see Figure 3). However, a significant number of participants $(17 \%)$ did not report their income on the survey. The segment of the population for whom English is not their primary language was not represented in the community flood risk management meetings (see Figure 5). 


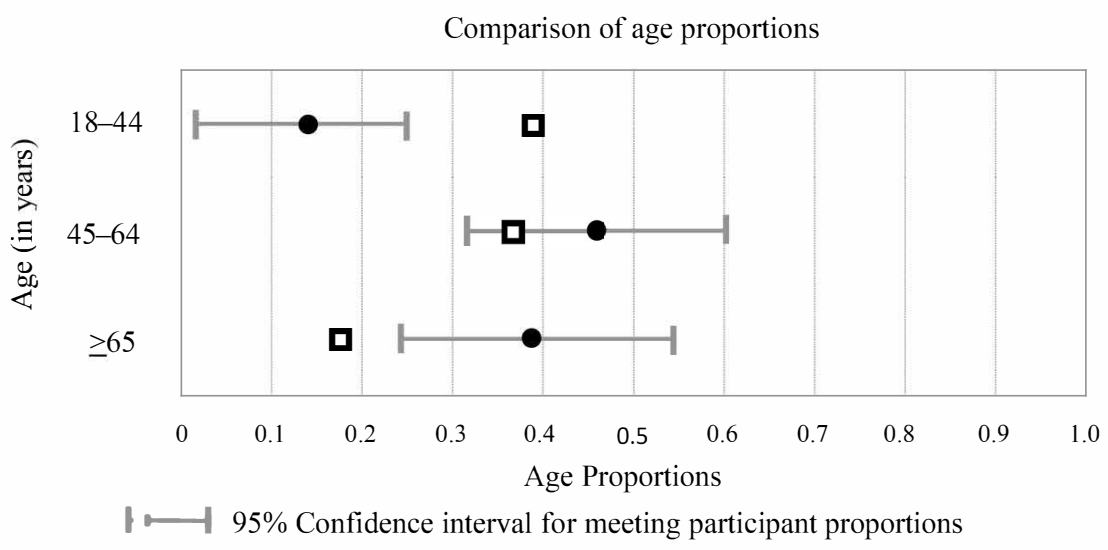

- Flood risk management meeting participants a FEMA Region III population

Figure 1. Comparison of age distributions for flood risk management meeting participants in 10 communities and the US Federal Emergency Management Agency (FEMA) Region III population

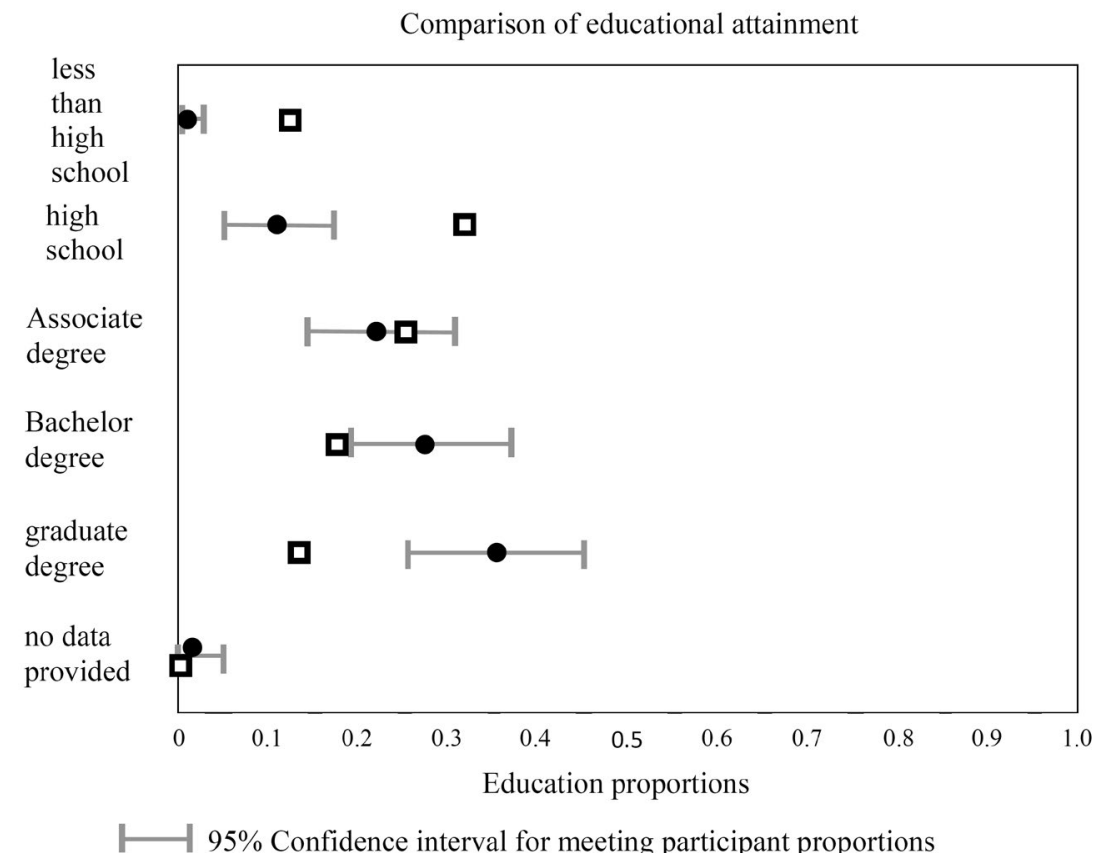

- Flood risk management meeting participants $\quad$ GEMA Region III population

Figure 2. Comparison of educational attainment for meeting participants in 10 communities and the US Federal Emergency Management Agency (FEMA) Region III population 


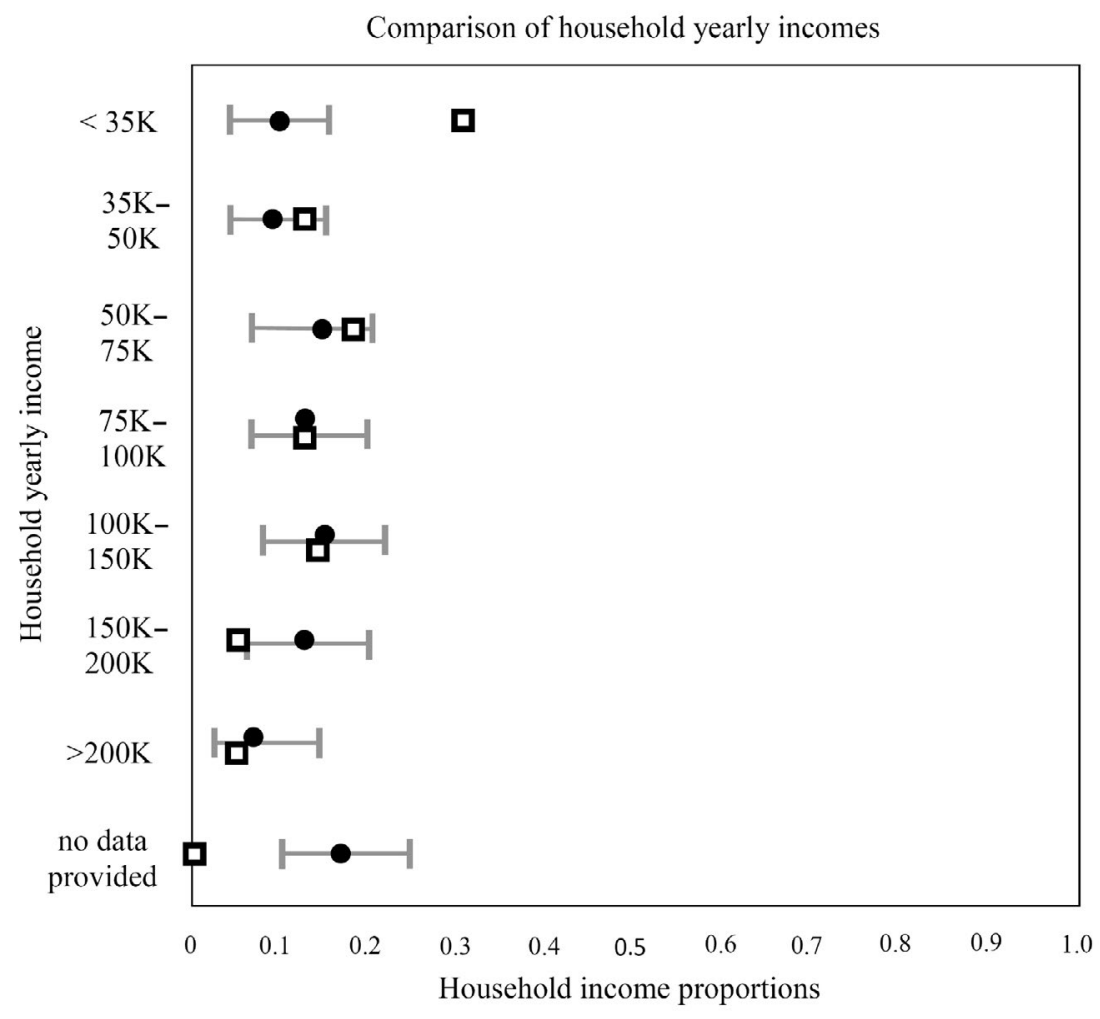

$\longmapsto$ - 95\% Confidence interval for meeting participant proportions

- Flood risk management meeting participants a FEMA Region III population

Figure 3. Comparison of household yearly incomes for meeting participants in 10 communities ( $K=\$ 1,000$, USD 2013) and the US Federal Emergency Management Agency (FEMA) Region III population $(\mathrm{K}=\$ 1,000$, USD 2010) 


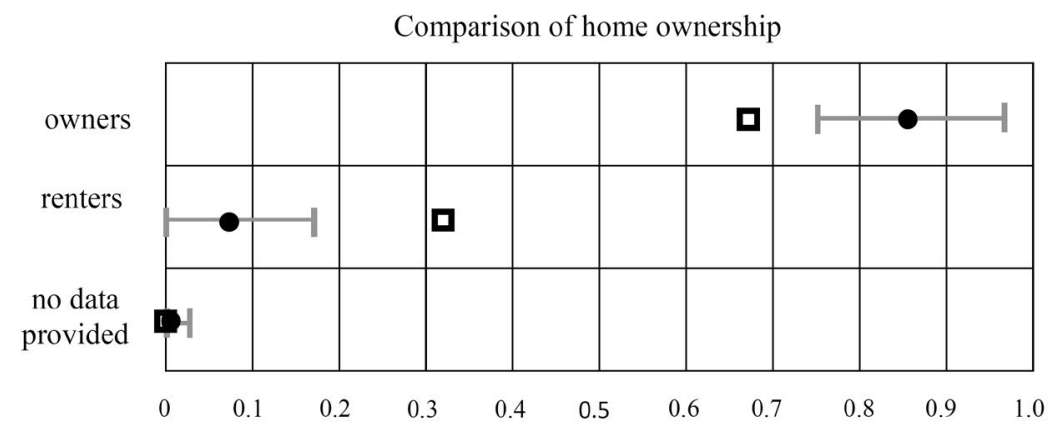

Home ownership proportions

$\longmapsto \quad \mid 95 \%$ Confidence interval for meeting participant proportions

- Flood risk management meeting participants 口 FEMA Region III population

Figure 4. Comparison of home ownership proportions for flood risk management meeting participants in 10 communities and the US Federal Emergency Management Agency (FEMA) Region III population

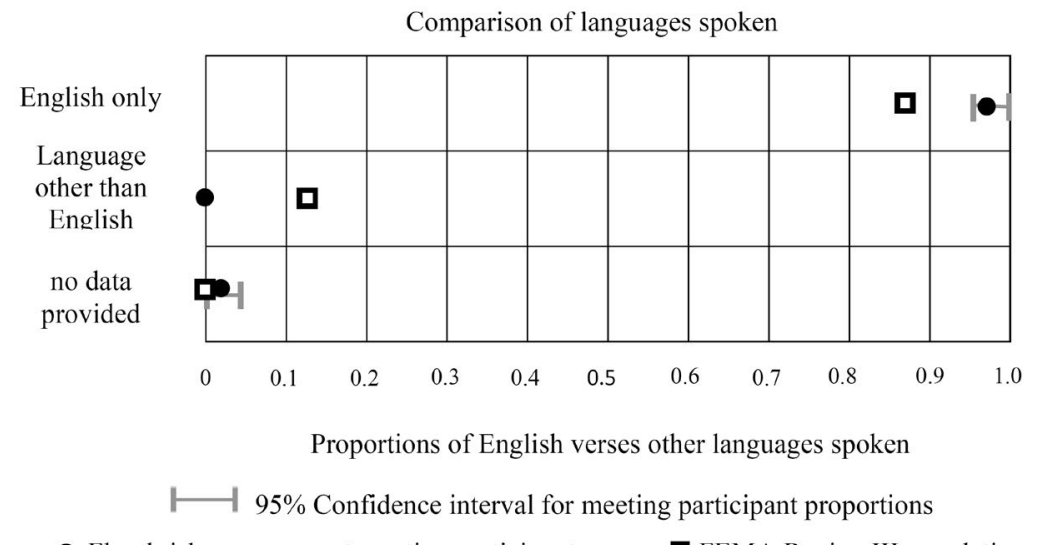

Figure 5. Comparison of languages spoken for the meeting participants in 10 communities and the US Federal Emergency Management Agency (FEMA) Region III population

There was no evidence of significant differences in race (see Figure 6) or gender (see Figure 7). Although statistically insignificant across all races, the "other" races category-including American Indian and Alaska Native, Native Hawaiian and other Pacific Islander, and "some other race"-was not represented within the communities. This group comprised $2.54 \%$ of the FEMA Region III population in the USCB 2010 census (USCB, 2010). 


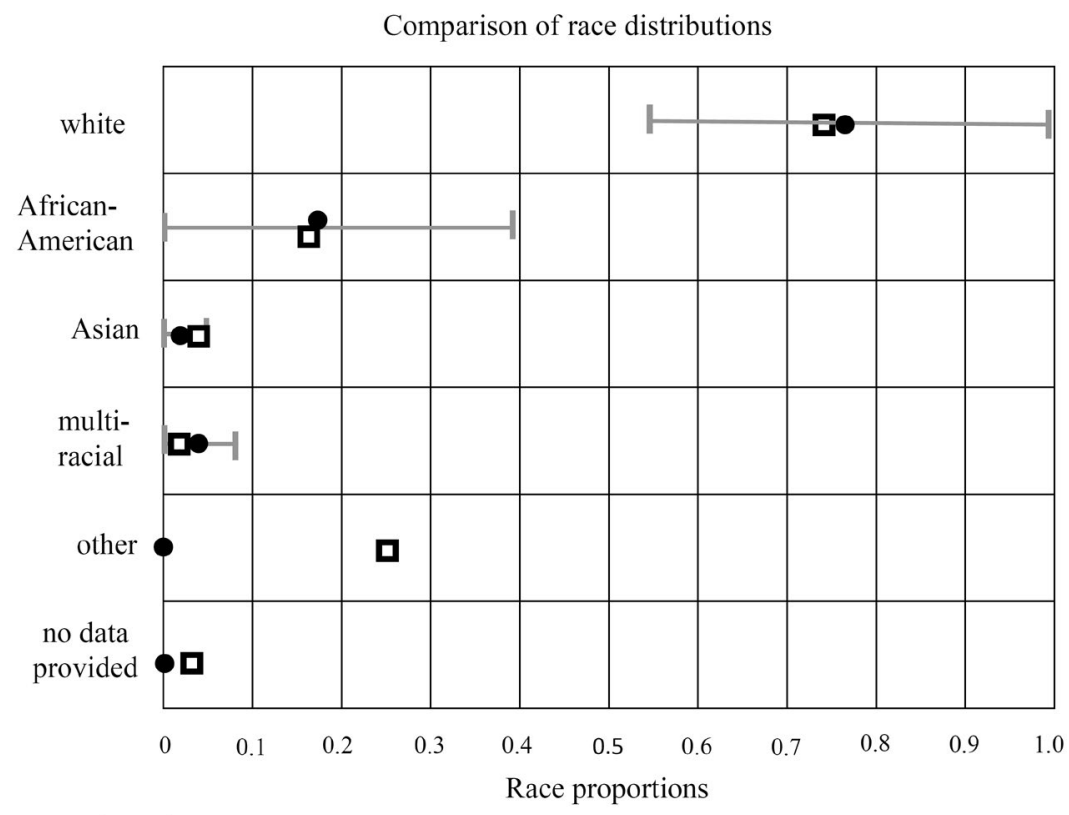

- 95\% Confidence interval for meeting participant proportions

- Flood risk management meeting participants

口 FEMA Region III population

Figure 6. Comparison of race distributions for the meeting participants in 10 communities and the US Federal Emergency Management Agency (FEMA) Region III population

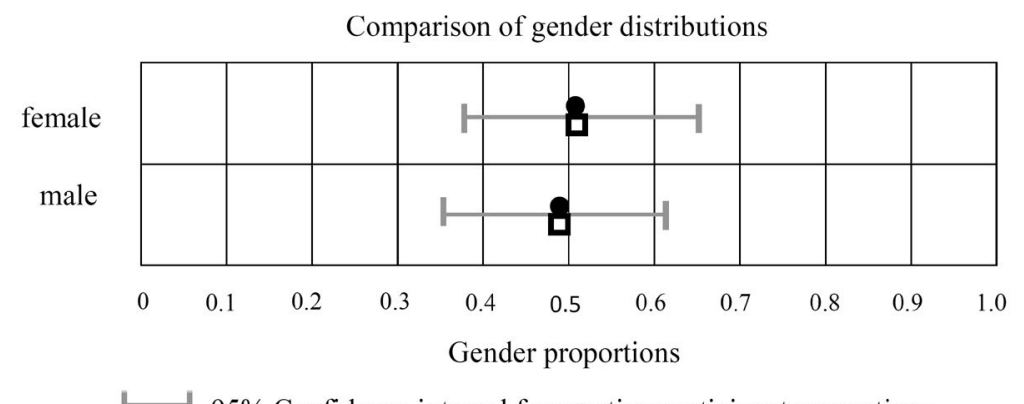

$\models-95 \%$ Confidence interval for meeting participant proportions
- Flood risk management meeting participants
口 FEMA Region III population

Figure 7. Comparison of gender distributions for the meeting participants in 10 communities and the US Federal Emergency Management Agency (FEMA) Region III population 
A cluster analysis was performed to compare the study communities to the general population based on all seven demographic characteristics (see Figure 8 and Figure 9). A unit (i.e., 10 EUs) that represented the aggregate of all 10 communities (see Figure 8 and Figure 9) was included in this analysis. Since the y-axis in Figure 8 indicates the proportion of multivariate information lost when clusters are joined, we may conclude that the 10 communities studied represented the FEMA Region III population well, given the small loss (approximately 2.5\%) of multivariate variation. Upon examining the demographic similarities among individual communities, one cluster (i.e., EU05, EU12, and EU20) of communities (see the cluster on the far right in Figure 9) shared approximately 55\% of their overall demographic character with the other communities, the aggregate of the 10 communities, and the FEMA Region III population (see Figure 9). The other communities were a closer match to one another, the aggregate of the 10 communities, and the FEMA Region III population.

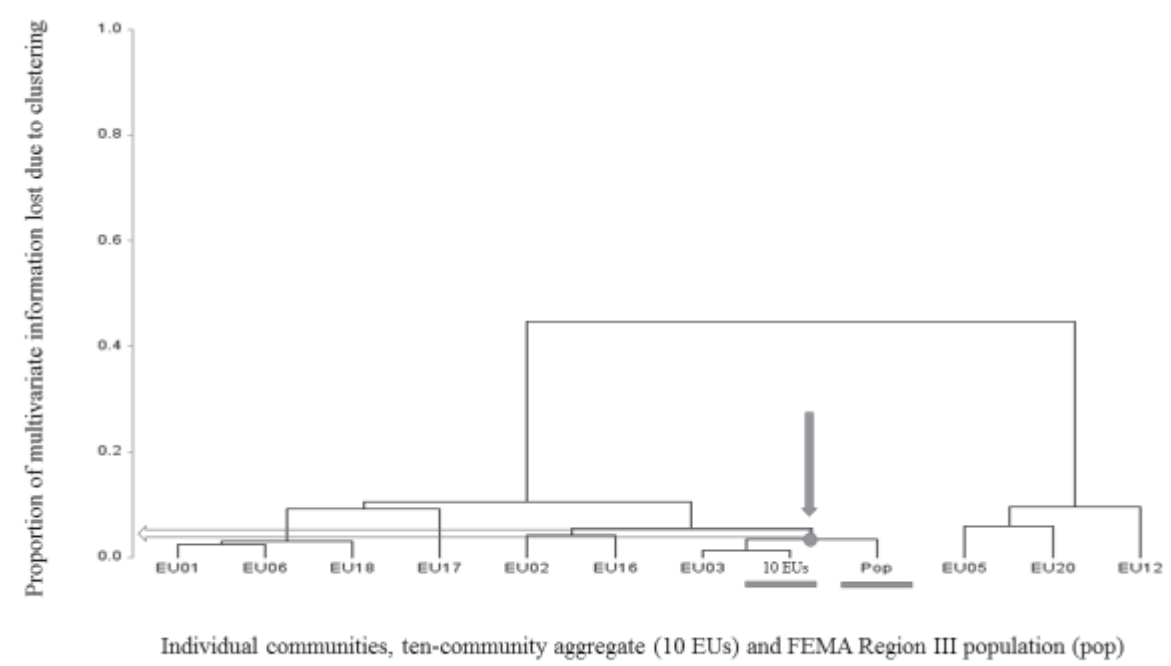

Figure 8. Demographic similarities of 10 communities that participated in flood risk management meetings compared to the data from the US Federal Emergency Management Agency (FEMA) Region III population

The vertical arrow points to the node of the cluster that contains the unit that represents the aggregate of all 10 communities (i.e., 10 EUs) and the Region III population (i.e., Pop). The horizontal arrow points to the proportion of information that is lost to form the cluster describing the aggregate and the population (approximately 0.025 on the $y$-axis).

Note. $E U(\#)=$ demographic characteristics of participants at a single community flood risk management meeting; $10 \mathrm{EUs}=$ demographic characteristics of participants in all 10 communities combined; Pop = demographic characteristics of the FEMA Region III population (USCB, 2010). 


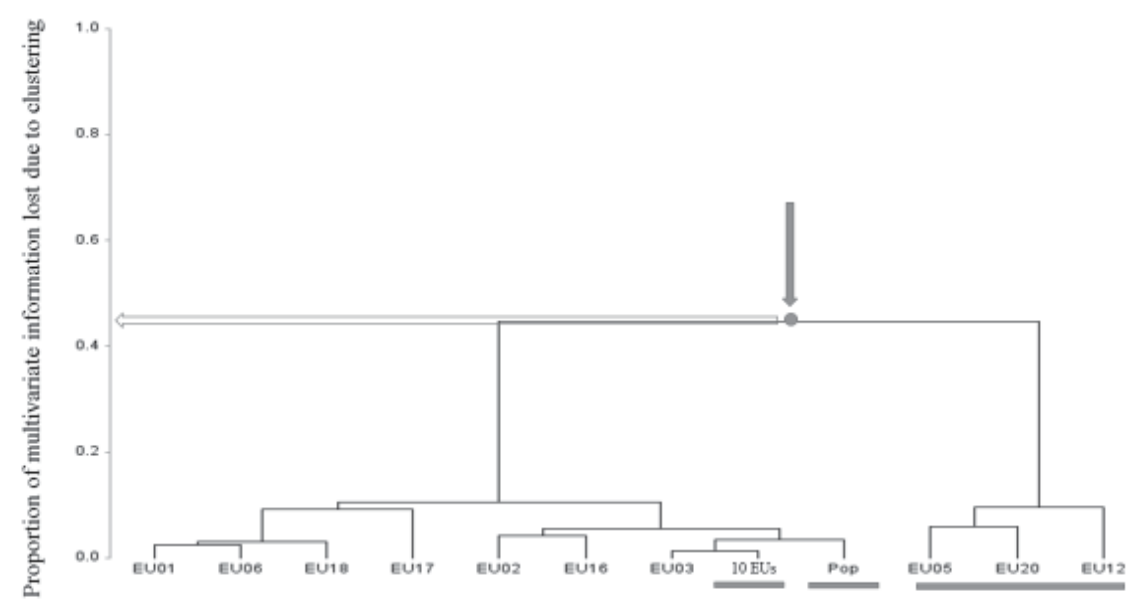

Individual communities, ten-community aggregate (10 EUs) and FEMA Region III population (pop)

Figure 9. Demographic similarities of 10 communities that participated in flood risk management meetings compared to the data from the US Federal Emergency Management Agency (FEMA) Region III population

The arrows indicate the point at which the most distant three-community cluster (i.e., EU05, EU12, and EU20) diverges from the other communities and the FEMA Region III population (i.e., Pop) in demographic similarity.

Note. EU $\#)$ = demographic characteristics of participants at a single community flood risk management meeting; $10 \mathrm{EUs}=$ demographic characteristics of participants in all 10 communities combined; Pop $=$ demographic characteristics of FEMA Region III population (USCB, 2010).

The results of the principal component analysis are summarized in Figure 10, which overlays the 10 study communities, FEMA Region III population, and vectors representing the demographic characteristics. The three communities located in the most distant cluster (i.e., cluster EU05, EU12, and EU20 in Figures 8 and 9) differed from the population (i.e., Pop in Figures 8, 9, and 10) by gender, in that there were more female participants (i.e., $\mathrm{F}$ in Figure 10). The three communities also differed by race, in that there were more African-American (i.e., B in Figure 10) and biracial (i.e., multi in Figure 10) participants, and by yearly household income, in that there were more participants with incomes of less than $\$ 35,000$ (USD 2013) (i.e., pov in Figure 10). 


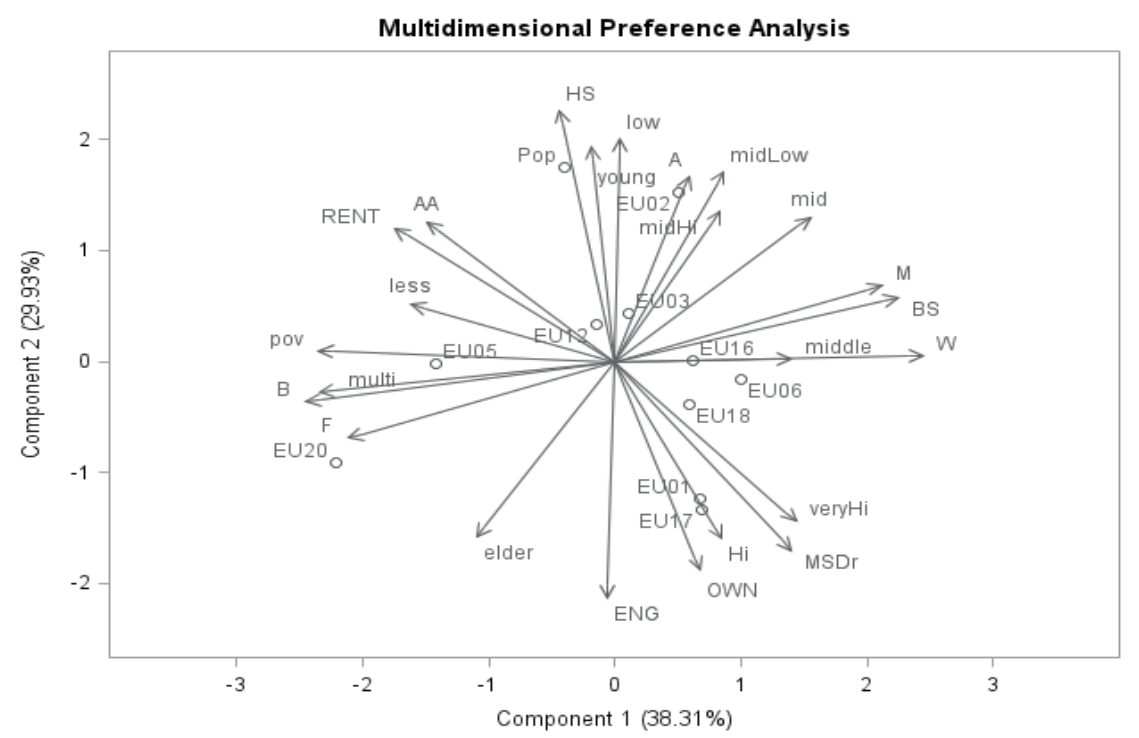

Figure 10. Multidimensional preference analysis based on the first two principal components showing relationships between the communities participating in flood risk management meetings, the US Federal Emergency Management Agency (FEMA) Region III population, and vectors representing the original demographic characteristics

The first and second principal components together explain 68.24\% (38.31 and 29.93\%, respectively) of the variation of the multiple demographic characteristics surveyed.

Note. EU $(\#)=$ demographic characteristics of participants at a single community flood risk management meeting; Pop = demographic characteristics of FEMA Region III population (USCB, 2010); Component 1 on $\mathrm{x}$-axis and Component 2 on $\mathrm{y}$-axis = combination of interdependent original variables that explains a percentage (shown in parentheses in axes labels) of the overall demographic character of participants in all 10 communities combined; Original demographic characteristics = principal component analysis symbol shown in the multidimensional preference analysis graphic with associated vector (key to symbols is located in the third column of chart below).

Table 1. Key to symbols in the multidimensional preference analysis in Figure 10

\begin{tabular}{|l|l|l|}
\hline $\begin{array}{l}\text { Demographic } \\
\text { characteristic }\end{array}$ & $\begin{array}{l}\text { Level within each demographic } \\
\text { characteristic }\end{array}$ & $\begin{array}{l}\text { Principal component analysis } \\
\text { symbol for each level within each } \\
\text { demographic characteristic }\end{array}$ \\
\hline \multirow{2}{*}{ Gender } & Female & F \\
\cline { 2 - 3 } & Male & M \\
\hline \multirow{3}{*}{ Age } & $\geq 65$ years & elder \\
\cline { 2 - 3 } & $45-64$ years & middle \\
\cline { 2 - 3 } & $18-44$ years & young \\
\hline \multirow{3}{*}{ Race } & Asian & A \\
\cline { 2 - 3 } & African-American & B \\
\cline { 2 - 3 } & White & W \\
\cline { 2 - 3 } & Multi-racial & multi \\
\hline
\end{tabular}


The Demographics of Public Participation Access When Communicating Environmental Risk

\begin{tabular}{|l|l|l|}
\hline $\begin{array}{l}\text { Demographic } \\
\text { characteristic }\end{array}$ & $\begin{array}{l}\text { Level within each demographic } \\
\text { characteristic }\end{array}$ & $\begin{array}{l}\text { Principal component analysis } \\
\text { symbol for each level within each } \\
\text { demographic characteristic }\end{array}$ \\
\hline \multirow{5}{*}{ Education } & Less than a high school diploma & less \\
\cline { 2 - 3 } & $\begin{array}{l}\text { High school diploma or } \\
\text { equivalency credential }\end{array}$ & HS \\
\cline { 2 - 3 } & Associate degree & AA \\
\cline { 2 - 3 } & Bachelor's degree & BS \\
\cline { 2 - 3 } & Graduate degree & MS/Dr \\
\hline Language spoken & English-only speakers & ENG \\
\hline Household yearly income & $<35 \mathrm{~K}(\mathrm{~K}=$ USD \$1, 000) & pov \\
\cline { 2 - 3 } & $35-50 \mathrm{~K}$ & low \\
\cline { 2 - 3 } & $50-75 \mathrm{~K}$ & midLow \\
\cline { 2 - 3 } & $75-100 \mathrm{~K}$ & mid \\
\cline { 2 - 3 } & $100-150 \mathrm{~K}$ & midHi \\
\cline { 2 - 3 } & $150-200 \mathrm{~K}$ & Hi \\
\cline { 2 - 3 } & $>200 \mathrm{~K}$ & VeryHi \\
\hline Home ownership & Own & RENT \\
\cline { 2 - 3 } & Rent & \\
\hline
\end{tabular}

\section{Discussion}

The results indicate that most demographic sectors of the FEMA Region III population were reached during flood risk management meetings. However, within the individual communities, there was often much less diversity. For example, some community meetings were represented primarily by low-income, African-American females. Others were represented mainly by middle-aged, white males with bachelor's degrees. The message from these findings is that it is important for city and county municipal environmental risk managers to organize community meetings in many local communities in their jurisdiction to capture all demographically diverse sectors. Other studies showed that racially segregated minority communities receive significantly fewer benefits associated with high-quality environmental planning (Glaeser \& Glaser, 2010; Saporito \& Casey, 2015). This study shows that racially segregated minority communities were interested in environmental issuesdemonstrated by their equal participation in flood risk management meetingscompared to racially segregated majority communities. In municipalities where local communities tend to be segregated, seeking to include all demographically distinct communities in participatory meetings may alleviate this environmental injustice.

Overall, the communities were representative of the general population. However, there were some significant differences when each demographic characteristic was analyzed independently. These results showed the study participants were 
significantly older, English-only speakers, better educated, from households earning more than $\$ 35,000$ (USD 2013) per year, and more likely to own a home than the USCB data indicate for the FEMA Region III population. In contrast to the findings from previous studies, females were as likely to attend meetings as males, minorities were represented equal to their proportion of the general population, and the elderly were well represented.

To communicate flood risk information to those segments of the population that were underrepresented, outreach methods need to be developed for young adults aged 18-44, speakers of languages other than English, those without a college education, those with incomes below $\$ 35,000$, and home renters. For some audiences, it is quite possible that a traditional meeting is not an appropriate venue for sharing necessary information.

The low representation of participants aged 18-20 could be due to the high mobility of this age group. Many are in temporary housing while attending college and may show less interest in attending local flood risk management meetings (Cutter et al., 2008). Since they do not plan to stay long in their present location, they may not consider it worth the investment of time and money to learn about flood risk and invest in reduction options. In college towns where this population is large, it may be advantageous for educational institutions to take the lead in expanding their flood preparedness to cover both on-campus dormitories and off-campus housing where student resident density is high. Low interest in risk reduction measures may also be due to the "invincible" attitude attributed to this age group, thinking they can survive a flood without much prior preparation.

The significantly low participation rates for the 18-44-year age group may be associated with this group being of child-bearing age. Of the 10 communities that volunteered to receive our flood risk information by self-selecting to participate in the study, 50\% did not have households with children under the age of 12 (USCB, 2010). Of those communities in which the USCB census information indicated childcare would be needed by some families, the community organizers did not arrange for childcare to be available during the meeting. Since there was no significant difference in gender attendance, if childcare is preventing this age group from participating then both parents are involved equally in the task of caring for young children. It is particularly important to reach this group since young children are highly vulnerable to morbidity and mortality during flood events (Suarez et al., 2009). The 18-44-year age group is also more likely to be in the early stages of their careers, in which they may have less flexibility in scheduling their work time around community meetings than is the case for older individuals, who are either at a more advanced stage in their career or are retired and may have more flexibility. 
The elderly were well represented at the meetings, particularly by those living independently in homes they own. In the communities participating in flood risk management meetings, $95 \%$ of participants older than 64 years of age owned their homes. This is good news because this segment of the population is highly vulnerable to the effects of flooding events (Cutter et al., 2000).

Those with disabilities are disproportionately affected by disasters, with a mortality rate two to four times higher than people without disabilities (Castro et al., 2017; Hiranandani, 2016). Our study did not directly measure participants with disabilities attending our community meetings. Since our study was conducted within a US university, we followed the guidelines for the disclosure of disabilities as described in the Family Educational Rights and Privacy Act (FERPA) (20 USC $\$ 1232$; 34 CFR Part 99). The law specifies that a physical or mental condition shall not be labeled as a disability unless the student voluntarily describes the condition as such and requests assistance. In the spirit of FERPA, we chose to apply these guidelines to our interaction with meeting participants. We had three participants, each from a different community, self-identify as visually impaired. For those individuals, we provided an assistant to read their surveys and modeling instructions. Community organizers chose the facilities at which our meetings were conducted. Only half of the communities located their meetings in facilities that met the accessibility requirements outlined in the Americans with Disability Act (ADA) of 1990. One unobtrusive way to help improve participation may be to ensure that the meeting place is easily accessible to mobility-impaired individuals and make sign language interpreters available upon request. One dilemma that arises is that the communities without an ADA-accessible facility may choose not to participate at all. Three of the five non-compliant communities were low income, including one historic town. In these cases, there did not appear to be a compliant building available within the community. Conversely, sign language interpreters could easily be made available by ensuring that at least one research assistant has these skills.

The segment of the population for whom their primary language is not English was without representation among the study participants. This is a growing sector in the US according to the USCB. The 2013 data from the USCB showed that one in five (21\%) US residents spoke a foreign language at home (USCB, 2013). Spanish was the non-English language most frequently spoken at home, followed by Chinese (USCB, 2013). In the US, how well a person speaks English may indicate how well he or she communicates with public officials and other service providers. People who do not have a strong command of English and do not have someone in their household to help them on a regular basis are defined by USCB as "linguistically isolated" (USCB, 2010). In 2013, of those who spoke a foreign language at home, $41 \%$ were linguistically isolated (USCB, 2013). With this trend toward an increased number of households speaking English as a second language or speaking no English, the total absence of these groups in the community flood risk management meetings 
in this study indicates that more effective methods of communicating flood risk to this sector are needed. For nine of the 10 communities in our study, information was available on the proportion of members who did not speak English well. Of these communities, $80 \%$ comprised members who either spoke only English or, if multilingual, spoke English very well. In the two communities reported to have members who did not speak English well, the proportion of the membership in that category was $4 \%$ and $13.7 \%$. Due to the English-only advertising and lack of translators during the meetings, these individuals were at a disadvantage for inclusion in the study.

Meeting participants without a college education and those with yearly household incomes below $\$ 35,000$ (USD 2013) were underrepresented in the community meetings. These segments of the population are particularly vulnerable during floods (Cutter et al., 2000; Cutter et al., 2008). Their participation may increase if the meetings were held in a familiar venue that offers a greater level of comfort, such as community buildings at which they often congregate for other activities.

Another segment of the population underrepresented in the community meetings was those that rent their homes. Renters may think of flood insurance as a tool useful only to those who own their property. Flood insurance is available through the US National Flood Insurance Program to cover the contents of a home and the cost of alternative housing (FEMA, 2011). Temporary alternative housing, such as hotel accommodation, may be more expensive than rent paid for regular housing. Therefore, both types of flood insurance could be useful to renters. In a US nationwide survey conducted by FEMA in 2012, almost 31\% of households believed that flood damage was covered by their homeowner's or renter's policy (FEMA, 2013). Since most of these policies do not cover damage resulting from floods, many think they are insured when they are not (FEMA, 2013). In this study, the demographics in the community meetings showed that homeowners were receiving that information but few renters were attending. Therefore, renters were not receiving the information they need to make fact-based decisions on reducing their flood risk.

Turnout at the flood risk management meetings was low, ranging from less than $1 \%$ to $24 \%$ of total membership. This is within the range of attendance documented in other studies for meetings requesting citizen engagement on environmental issues (Chhetri \& Grossman, 2012; Leach, 2002, 2004; Lubell \& Leach, 2005; Rask \& Worthington, 2012; Sclove, 2010; Worthington et al., 2012; Tomblin et al., 2015). However, it would be worthwhile to investigate other forms of communication that may attract larger proportions of community members, particularly in light of new communication media available through the Internet (Sclove, 2010). 
In summary, this study found that most demographic sectors of the FEMA Region III population were reached during flood risk management meetings. However, there was often much less diversity within the individual communities. While overall, the communities were representative of the general population, there were some significant differences when each demographic characteristic was independently analyzed. These results showed the study's participants were significantly older, English-only speakers, better educated, from households earning more than $\$ 35,000$ (USD 2013) per year, and more likely to own a home than the USCB data indicate for the FEMA Region III population. In contrast to the findings of previous studies, females were as likely to attend meetings as males, minorities were represented equal to their proportion of the general population, and the elderly were well represented. Better outreach methods need to be developed for young adults aged 18-44, speakers of languages other than English, those without a college education, those with incomes below $\$ 35,000$, and home renters.

\section{References}

Aberman, N. L., Ali, S., Behrman, J., Bryan, E., Davis, P., Donnelly, A., \& Okoba, B. (2015). Climate change adaptation assets and group-based approaches: Gendered perceptions from Bangladesh, Ethiopia, Mali, and Kenya (Discussion Paper 01412). Retrieved from: ebrary.ifpri.org/cdm/ref/collection/p15738coll2/id/128950

Abrahamse, W., \& Steg, L. (2015). Factors related to household energy use and intention to reduce it: The role of psychological and socio-demographic variables. Human Ecology Review, 21(2), 30-40.

Adger, W. N., Kelly, P. M., \& Ninh, N. H. (2001). Environment, society and precipitous change. In W. N. Adger, P. M. Kelly \& N. H. Ninh (Eds.), Living with environmental change: Social vulnerability, adaptation and resilience in Vietnam (pp. 3-18). London, UK: Routledge.

Atreya, A., Ferreira, S., \& Michel-Kerjan, E. (2015). What drives households to buy flood insurance? New evidence from Georgia. Ecological Economics, 117, 153-161. doi.org/ 10.1016/j.ecolecon.2015.06.024

Brown, H. L., Bos, D. G., Walsh, C. J., Fletcher, T. D., \& RossRakesh, S. (2016). More than money: How multiple factors influence householder participation in at-source stormwater management. Journal of Environmental Planning and Management, 59(1), 79-97. doi.org/10.1080/09640568.2014.984017

Bullinger, H.J., Ziegler, J., \& Bauer, W. (2002). Intuitive human-computer interactiontoward a user-friendly information society. International Journal of Human-Computer Interaction, 14(1), 1-23. doi.org/10.1207/S15327590IJHC1401_1 
Castro, C. P., Sarmiento, J. P., Edwards, R., Hoberman, G., \& Wyndham, K. (2017). Disaster risk perception in urban contexts and for people with disabilities: Case study on the city of Iquique (Chile). Natural Hazards, 86(1), 411-436. doi.org/10.1007/s11069016-2698-x

CFI (Claes Fornell International Group). (2010). FEMA citizen questionnaire. PennWell Corporation.

Chhetri, N., \& Grossman, G. M. (2012). Policy makers versus people. The Cairo Review of Global Affairs, 5, 118-125.

Cutter, S. L., Barnes, L., Berry, M., Burton, C., Evans, E., Tate E., \& Webb J. (2008). A place-based model for understanding community resilience to natural disasters. Global Environmental Change, 18(4), 598-606. doi.org/10.1016/j.gloenvcha.2008.07.013

Cutter, S. L., Boruff, B. J., \& Shirley, W. L. (2003). Social vulnerability to environmental hazards. Social Science Quarterly, 84(2), 242-261. doi.org/10.1111/1540-6237.8402002

Cutter, S. L., Burton, C. G., \& Emrich, C. T. (2010). Disaster resilience indicators for benchmarking baseline conditions. Journal of Homeland Security and Emergency Management, 7(1). doi.org/10.2202/1547-7355.1732

Cutter, S. L., Mitchell, J. T., \& Scott, M. S. (2000). Revealing the vulnerability of people and places: A case study of Georgetown County, South Carolina. Annals of the Association of American Geographers, 90(4), 713-737. doi.org/10.1111/0004-5608.00219

FEMA (Federal Emergency Management Agency). (2011). Answers to questions about the national flood insurance program (FEMA F-084). Retrieved from: www.fema.gov/medialibrary-data/20130726-1438-20490-1905/f084_atq_11aug11.pdf

FEMA (Federal Emergency Management Agency). (2013). 2012 Public survey findings on flood risk. Retrieved from: www.fema.gov/media-library-data/20130726-1923-25045-6047/ keytakeaways2012publicsurvey.pdf

FEMA (Federal Emergency Management Agency). (2014). FEMA region III. Retrieved from: www.fema.gov/region-iii-dc-de-md-pa-va-wv

Glaeser, B., \& Glaser, M. (2010). Global change and coastal threats: The Indonesian case. An attempt in multi-level social-ecological research. Human Ecology Review, 17(2), $135-147$.

Hiranandani, V. (2016). Disability in humanitarian emergencies in India: Towards an inclusive approach. In M. Gill \& C. J. Schlund-Vials (Eds.), Disability, human rights and the limits of humanitarianism (pp. 101-118). London, UK: Routledge.

Hvistendahl, M. (2012). Gender and violence. Science, 336(6083), 839-840. doi.org/ $10.1126 /$ science.336.6083.839 
Ibarrarian, M. E., \& Ruth, M. (2009). Climate change and natural disasters: Economic and distributional impacts. In M. Ruth and M. E. Ibarrarian (Eds.), Distributional impacts of climate change and disasters: Concepts and cases (pp. 46-66). Northampton, MA: Edward Elgar. doi.org/10.4337/9781849802338.00010

Leach, W. D. (2002). Surveying diverse stakeholder groups. Society \& Natural Resources, 15(7), 641-649. doi.org/10.1080/08941920290069245

Leach, W. D. (2004). Is devolution democratic? Assessing collaborative environmental management. doi.org/10.2139/ssrn.628122

Leach, W. D. (2006a). Collaborative public management and democracy: Evidence from Western watershed partnerships. Public Administration Review, 66(s1), 100-110. doi.org/10.1111/j.1540-6210.2006.00670.x

Leach, W. D. (2006b). Public involvement in USDA Forest Service policymaking: A literature review. Journal of Forestry, 104(1), 43-49.

Leach, W. D., Pelkey, N. W., \& Sabatier, P. A. (2002). Stakeholder partnerships as collaborative policymaking: Evaluation criteria applied to watershed management in California and Washington. Journal of Policy Analysis and Management, 21(4), 645-670. doi.org/10.1002/pam.10079

Lubell, M., \& Leach, W. D. (2005). Watershed partnerships: Evaluating a collaborative form of public participation. Prepared for the National Research Council's Panel on Public Participation in Environmental Assessment and Decision Making, February 3-4, National Academy of Sciences, Washington, DC.

Miller, G. (2012). Getting minds out of the sewer. Science, 337(6095), 679-680. doi.org/ $10.1126 /$ science.337.6095.679

Patt, A. G., Daze, A., \& Suarez, P. (2009). Gender and climate change vulnerability: What's the problem, what's the solution? In M. Ruth and M. E. Ibarrarian (Eds.), Distributional impacts of climate change and disasters: Concepts and cases (pp. 82-102). Northampton, MA: Edward Elgar. doi.org/10.4337/9781849802338.00013

Rask, M., \& Worthington, R. K. (2012). Prospects of deliberative global governance. Journal of Environmental Science and Engineering. B 1(4B), 556-565.

Saporito, S., \& Casey, D. (2015). Are there relationships among racial segregation, economic isolation, and proximity to green space? Human Ecology Review, 21(2), 113-132. doi.org/10.22459/HER.21.02.2015.06

Sclove, R. (2010). Reinventing technology assessment: A 21st century model. Retrieved from: www.loka.org/documents/reinventingtechnologyassessment1.pdf

Suarez, P., Ribot, J. C., \& Patt, A. G. (2009). Climate information, equity and vulnerability reduction. In M. Ruth and M. E. Ibarrarian (Eds.), Distributional impacts of climate change and disasters: Concepts and cases (pp. 151-165). Northampton, MA: Edward Elgar. doi.org/10.4337/9781849802338.00016 
Tomblin, D., Worthington, R., Gano, G., Farooque, M., Sittenfeld, D., \& Lloyd, J. (2015). Informing Nasa's asteroid initiative: A citizen's forum. Final results report. Retrieved from: ecastnetwork.files.wordpress.com/2015/09/nasa-asteroid-initiative-citizen-forumfull-report.pdf

USCB (United States Census Bureau). (2010). American fact finder: Community facts. Retrieved from: factfinder.census.gov/faces/nav/jsf/pages/index.xhtml

USCB (United States Census Bureau). (2013). American community survey. Retrieved from: www.census.gov/programs-surveys/acs/

Worthington, R., Cavalier, D., Farooque, M., Gano, G., Geddes, H., Sander, S., Sittenfeld, D., \& Tomblin, D. (2012). Technology assessment and public participation: From TA to pTA. Retrieved from: ecastnetwork.files.wordpress.com/2013/01/ecast-report-ta-topta-rev1.pdf 
This text is taken from Human Ecology Review, Volume 24, Number 1, 2018, published 2018 by ANU Press, The Australian National University, Canberra, Australia.

doi.org/10.22459/HER.24.01.2018.06 